\title{
A educação em saúde no ambiente de sala de espera
}

\author{
Ana Luísa Gerheim, Aline Kalam, Yara Sandim
}

\section{Resumo}

A realização da educação em saúde nas salas de espera é uma prática que vem crescendo a cada dia, pois é um local onde os usuários aguardam com um tempo ocioso o atendimento dos profissionais, tornando-se assim, um adequado ambiente, para a integração, escuta, acolhimento e aprendizagem. Essa prática baseia-se em ações que incentivam a participação dos usuários na construção do seu conhecimento sobre temas relacionados a saúde, e na de prevenção e promoção em saúde. $\mathrm{O}$ presente trabalho teve como objetivo, prover encontros de conversas orientadas sobre temas relacionados à saúde; encorajar a participação dos usuários na construção do seu conhecimento; cooperar na educação em saúde dos usuários; otimizar o tempo de espera do usuário; promover saúde e atender à Lei do Exercício Profissional da Enfermagem, à Política Nacional de Promoção à Saúde e à Política de Humanização do SUS. Trata-se de um relato de experiência das atividades realizadas em salas de esperas dos ambulatórios do $1^{\circ}$ e $2^{\circ}$ andar, dos setores de endoscopia, métodos gráficos, fisioterapia, laboratório e imagem em geral do Hospital Universitário de Juiz de Fora, realizadas entre o mês de abril e julho de 2016, pelas acadêmicas do $7^{\circ}$ período de enfermagem da Universidade Federal de Juiz de Fora. Foram utilizados além da exposição oral, recursos como mídia, e folders, para melhor fixação e abordagem dos seguintes temas de relevância situacional: Influenza H1N1, Dengue, Doação de Sangue, Fluxo de Atendimento, Diabetes e Hipertensão. Foram realizados 66 encontros, com no mínimo 30 pessoas, de diversas faixas etárias e diagnósticos, proporcionando uma interação entre e acadêmicas e usuários. Julgando a realização desses encontros uma ação efetiva na educação em saúde, devido ao grande número de participação, exposição de experiências vividas, questionamentos levantados pelas pessoas durante e após a abordagem da temática escolhida. Podemos considerar as ações educativas de saúde em sala de espera como um instrumento fundamental, na promoção e prevenção de saúde, em todos os níveis de atendimento, devido à facilidade de acesso, de integração, e forma de transmissão das informações nestes ambientes.

Descritores: Educação em saúde, Sala de espera, Promoção de saúde. 